\title{
COVID-19 pandemic: Preparation of the department of anesthesiology and pain medicine in a tertiary care hospital of a low income country
}

\author{
Sana'a Afzal Khan, Wajahat Nazir Ahmed, Muhammad Hasnain Chatha, Asma Ashraf Khan, \\ Ahsun Waqar Khan
}

Affiliation: Department of Anesthesiology, Pain \& Intensive Care, Shaukat Khanum Memorial Cancer Hospital and Research Center (SKMCH \& RC), Johar Town, Lahore, Pakistan.

Correspondence: Dr. Sana'a Afzal Khan, House \# 27/2, Sector-G, Street 5, Phase 5, DHA, Lahore, Pakistan; E-mail: sanaa.a.khan7@gmail.com; Phone: 0321-4349731

\section{Abstract}

The COVID-19 pandemic -, a global health crisis has come as a great challenge to even the most advanced healthcare systems around the world. Pakistan has a poorly developed healthcare infrastructure to effectively cope with the pandemic.

In view of this, it was appropriate to anticipate that Pakistan's state of preparedness might prove to be inadequate if and when the disease became rampant. It was also important to note that countries which prepared preemptively for the crisis and responded timely were able to cope with it better than others. This realization prompted a need for formulation of a strategy to manage the fallout expected from a high number of COVID-19 cases.

Shaukat Khanum Memorial Cancer Hospital and Research Center (SKMCH \& RC) is a research-based tertiary care center in a low resource-income country. Having previous experience in devising strategic healthcare guidelines, we at SKMCH \& RC created a comprehensive plan for the department of anesthesia and pain medicine, with the specific aim of improving our ability to deal with the ongoing crisis. We believed that our plan might be applied across the region, where limited availability of resources is a common theme.

The plan of action was divided into three phases: planning, preparation and implementation. A team of anesthetists was formed and tasked with performing a thorough review of international guidelines and literature on the subject. The next step was to compile the findings and create tailored solutions for successful application in a resource-poor environment. The report further explains the procurement and mobilization of necessary resources at the hospital level as warranted by the plan. Lastly, the report shares knowledge on how the plan was practically implemented across operating rooms and intensive care units at SKMCH \& RC. It is hoped that this review will enable low-budget healthcare facilities to implement and benefit from our plan.

Citation: Khan SA, Ahmed WN, Chatha MH, Khan AA, Khan AW. COVID-19 pandemic: Preparation of the department of anesthesiology and pain medicine in a tertiary care hospital of a low income country. Anaesth. pain intensive care 2020;24(4):440449.

Received: 9 July 2020, Reviewed: 31 July 2020, Revised: 10 August 2020, Accepted: 10 August 2020

\section{Introduction}

On $31^{\text {st }}$ December 2019, the WHO China country office was notified about Pneumonia related illness with unknown etiology in the city of Wuhan, Hubei province of China. Reportedly, the testing authorities were able to isolate the causal agent by $7^{\text {th }}$ January 2020. ${ }^{1}$
COVID-19, which stands for The Coronavirus Disease of 2019, is an acute infection consisting of nonspecific syndromes including respiratory (cough, shortness of breath, rhinorrhea, hemoptysis), gastrointestinal (diarrhea, nausea, vomiting), musculoskeletal (muscle ache), and neurological (headache, confusion), with severe cases frequently progressing to Acute Respiratory Distress Syndrome 
(ARDS) and multiple organ failure. ${ }^{2}$ Although the exact mechanism of its transmission is still being researched, there is strong evidence that it occurs through respiratory droplet/secretion and direct contact. $^{3}$

On $30^{\text {th }}$ January 2020, WHO declared SARS- CoV-2 outbreak a global public health emergency, ${ }^{4}$ and subsequently on $11^{\text {th }}$ March 2020 , WHO declared SARS-CoV-2 a pandemic with rapidly rising number of cases worldwide, which have escalated to $12,197,843$ at the time of writing. The number of reported cases in Pakistan on 09/07/2020 is 240,848 with a total of 4983 deaths. ${ }^{5}$

The count worldwide continues to increase at near exponential rate. The total number of cases is likely to grow in the coming days. As of now, it is difficult to produce an accurate prediction owing to the high number of variables that may be at play.

Currently, we have very limited knowledge about the etiological agent, clinical manifestations, appropriate diagnostic tools, prognosis and possible treatment options. However, data from the previous SARS-CoV 2002-2003 outbreak has allowed us to determine certain characteristics of the virus, susceptible populations and the possible modes of transmission. ${ }^{6}$

Previous pandemics have shown that during outbreak, certain strategies have had to be employed for redressing the balance between required capacity, staff, medical supplies, equipment available at a medical institution and the overwhelming number of patients. $^{7}$ For communicable diseases, additional measures such as infection control ought to be implemented, which may include containment and quarantine. $^{8}$ The implementation of the aforementioned course of action may prove challenging in the operating room.

As of now, it is difficult to determine what the disease burden will be in the next few days and the magnitude of patients requiring emergency/urgent surgeries or ICU admissions. Therefore, anticipatory preparations are being made based on suppositions drawn from the experiences gained from hospitals worldwide..$^{9-10}$

The National Institute for Occupational Safety and Health (NIOSH) is a part of the U.S. Centers for Disease Control and Prevention (CDC), in the U.S. Department of Health and Human Services.
The aim of this research agency was to advocate and implement the necessary steps to safeguard the health and well-being of the workers in a particular environment. One of the methods to achieve this is the control of exposure to occupational hazards; this example is applicable in a pandemic and can be easily

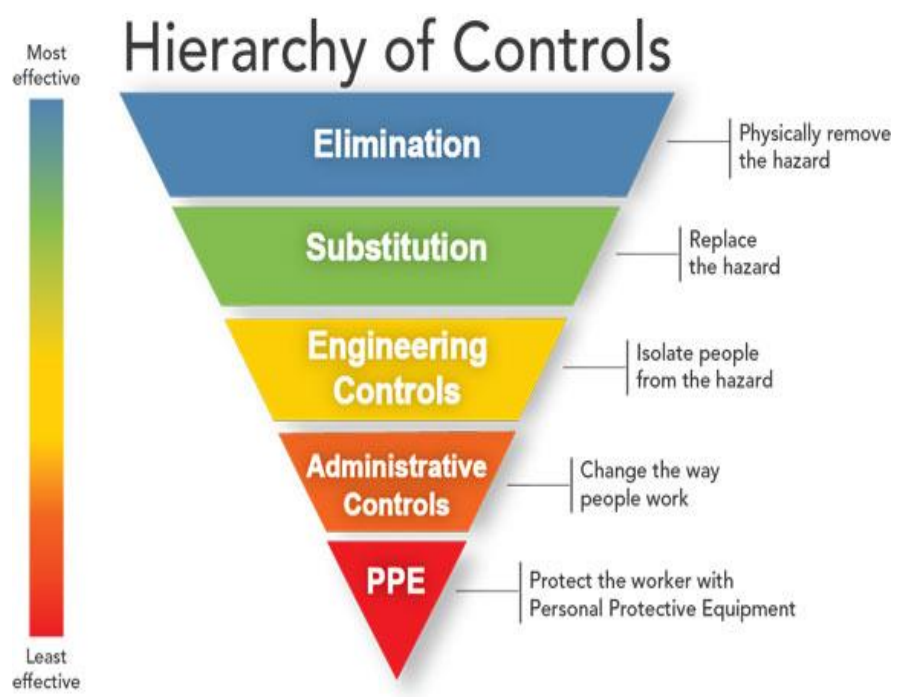

explained through means of the illustration (Figure 1).

Figure 1: An illustration showing hierarchy of control. ${ }^{11}$

\section{Hierarchy of controls}

This model has been followed as a part of an infection control plan. It shows that where elimination and substitution is possible, it is by far the most effective approach to protect healthcare workers.

\subsection{Elimination}

For elimination of the virus, the hospital set up a COVID camp in the parking area for triage of patients to assess if they have any symptoms before letting them enter the hospital premises. If the patient is suspected to be COVID-19 positive, a nasal swab is taken for PCR and the patient is advised to isolate at home until their test results are received. Patients who fulfill the criteria of admission are admitted to the isolation ward designated for COVID-19 patients, and this area is cordoned off to control the spread of the virus. Screening of employees working in clinical areas is done daily before the start of each shift, any employee suspected to be COVID-19 positive is tested immediately and advised to refrain from clinical activity and self-isolate until confirmatory results. 


\subsection{Engineering Controls}

Next step of value is the engineering controls, which is of utmost relevance. By creating negative pressure rooms in ICUs and COVID-19 dedicated wards, it is made certain that the viral load outside the room is kept at minimum. Furthermore, operating rooms undergo more than 20 air changes per hour to decrease viral load within the theaters. The hospital has been divided into three zones (red, yellow, green) based on risk assessment. PPE guidelines are followed based on what zone they fall in.

\subsection{Administrative Changes}

Administrative changes were carried out with the aim of making resources available and training staff to take appropriate measures such as social distancing and hand hygiene during this pandemic.

\subsection{Personal Protective Equipment}

Lastly, personal protective equipment (PPEs) were provided.

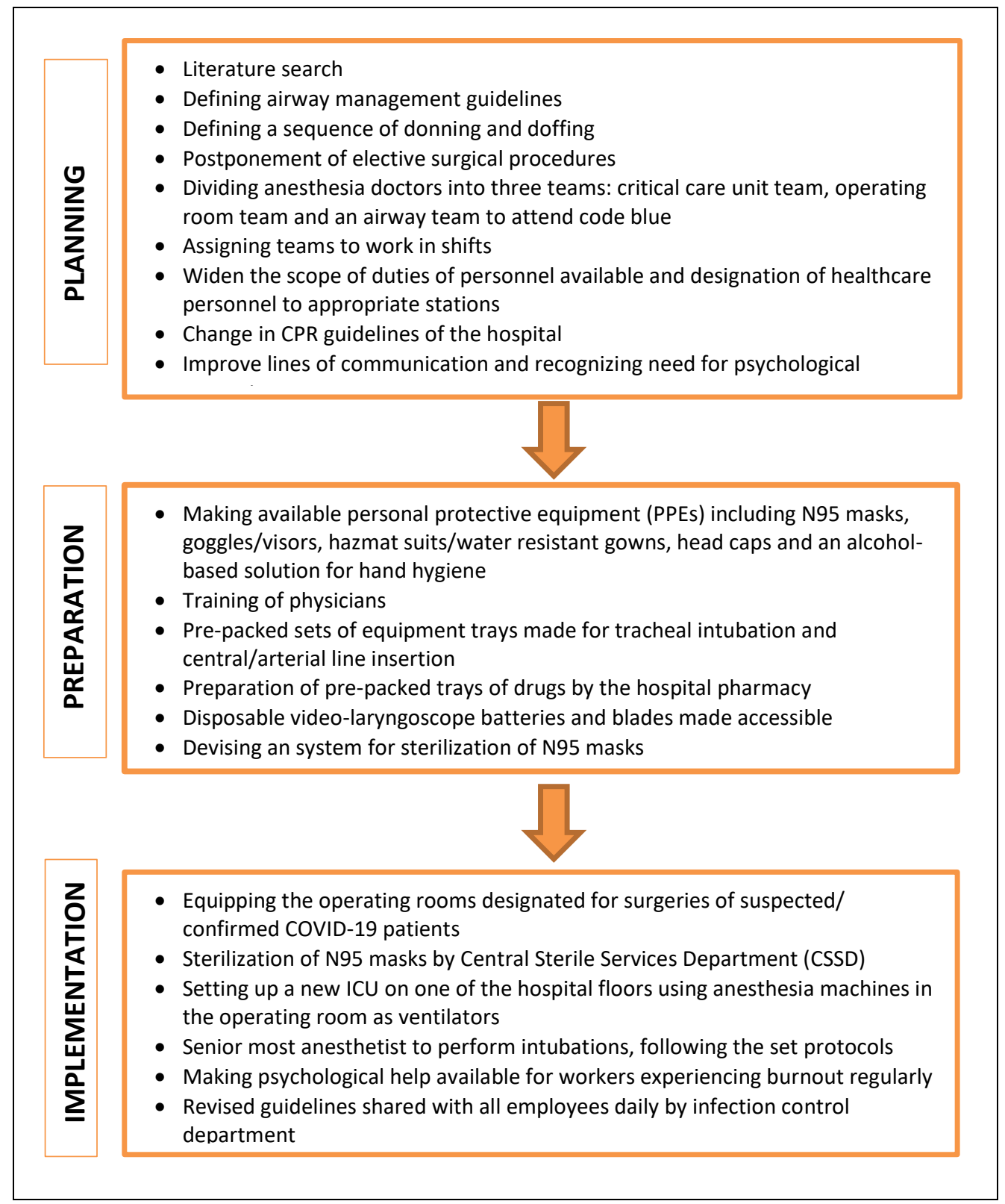

Figure 2: The framework for devising COVID-19 strategy 


\section{Planning}

A team of anesthetists was tasked with the development of airway management guidelines at par with international practice under the current crisis. We adopted a two-stage approach to the literature review. The first step was to identify texts and research papers, this was done to 1) Identify sequentially the research that was influencing the development of guidelines in this pandemic and 2) to use these texts as foundation for building subsequent protocols.

A systematic review of research articles and texts published from 2004 to 2020 was conducted using rigorous searching on three bibliographic databases namely Google Scholar, Medline and Embase. The keywords used were 'COVID-19', 'intubation', 'guidelines', 'PPEs', 'hospital policy' and 'SARS'. Thirty articles were highlighted and sixteen were considered to be relevant including guidelines from CDC, AAGBI and Royal College of Anesthetists. The results were subjected to peer review and a theoretical framework was developed for incorporation of recommendations which could be tailored to local needs and resources.

Initially at Shaukat Khanum Memorial Cancer Hospital and Research Centre, certain urgent procedures were being carried out. However, elective surgeries had been postponed in light of the pressing demand for resources. This step held paramount significance because it allowed for an increase in anesthesia machines available as ventilators to meet with expected excessive demand, and an increase in the staff whose services could be rendered useful in intensive care units.

The workforce in the department of anesthesia including consultants, senior instructors, fellows, residents and technicians, was divided systematically into morning and evening shifts. This decreased the contact with patients to a minimum with the aim to prevent the employees from being overtaxed.

Gradually, the elective surgical lists were restarted after devising a clear plan. Every patient undergoing elective surgical procedure at Shaukat Khanum Memorial Cancer Hospital and Research Centre is required to undergo testing via nasopharyngeal swab for detection of SARS-CoV-2 through polymerase chain reaction (PCR) within 48 hours of surgery. The patients are advised to self-isolate following submission of sample for testing, and elective procedure is carried out if the PCR test results are negative. Surgery for COVID-19 positive patients is carried out on emergency basis only. In the event of an emergency, one operation theatre is designated to cater to the COVID-19 positive patient. The procedure is planned and conducted out of regular hospital hours, if possible, to minimize patient flow and the number of personnel working in the operation theatre complex. To prevent cross contamination, such cases are recovered inside the operating rooms after completion of the surgical procedure and shifted directly to the COVID ward or COVID ICU by the team attending the patient intraoperatively.

In view of the current situation, administrative measures have been taken, which include designation of staff for specific duties to ensure efficient flow of work, division of duties to minimize the risk of burnout amongst employees and assigning nonclinical jobs to healthcare workers who are susceptible to developing complications related to the disease i.e. immuno-compromised persons and pregnant workers.

An unprecedented decision was made that elective intubations on patients with confirmed or suspected COVID-19 would only be performed by anesthesia consultants, at all hours. This was driven by the thought process that intubation by senior most anesthetist would decrease exposure time during aerosol generating procedure and ensure higher probability of success. Plans for an in-house anesthesia consultant working in shifts of twenty four hours each were also proposed should the disease burden increase. As the situation evolved, it was decided that elective intubations of patients with confirmed or suspected COVID-19 will be done by the senior most anesthetist available, not necessarily anesthesia consultants.

Newly developed airway management plans differ from previous clinical practice. In the operating room, after donning personal protective equipment, the patient's face is covered by a clear plastic sheet with a hole in the area directly covering the mouth, where the facemask is placed to prevent direct contact with any part of the patient's face. Pre-oxygenation for at least 5 minutes is recommended because these patients are anticipated to have respiratory distress secondary to Pneumonia or Acute Respiratory Distress Syndrome (ARDS), which could significantly affect their oxygen 
reserves. Bag mask ventilation is avoided due to risk of aerosol production unless patient is desaturating in which case low volume, low pressure bag mask ventilation may be done.

In addition, for patients with COVID-19, all electronic medical devices and if required ultrasound machines are covered with disposable plastic sheets.

Pre-oxygenation is achieved using a tightly-fitted facemask and closed circuit. The possibility of contamination via aerosol necessitates the use of heat moisture exchanger (HME) filters in all closed circuits. The filter is placed between patient interface (facemask) and circuit. If there are any secretions during the process of detaching the circuit and switching to the ventilator tubing, they would pass through the HME filter before entering the environment.

Since the process of intubation has been deemed as one of the aerosol generating procedures, the use of videolaryngoscope is advocated which would help maintain distance from the patient and ensure intubation without having to bend. This is will prevent close contact with the patient's mouth for visualization of vocal cords. This step is critical because aerosols can cause high viral load transmission. If intubation grade is considered greater than one, assistive devices such as bougie are used to avoid multiple attempts with conventional means, which unnecessarily increases exposure time

Intubation is carried out with rapid sequence induction using suxamethonium. During the course of the procedure, the movement of staff in and out of the OR is restricted and doors remain closed at all times.

For enhanced protection, anesthetists are instructed to clamp the endotracheal tube while switching to ventilatory support. Prior to intubation, one of the colleagues is assigned the task to reduce oxygen flow and attach the ventilator, already set with required parameters for the specific patient. The patient is ventilated only after inflating the cuff on the endotracheal tube. For intubations being performed at any place other than the operating room such as in the ICU or the isolation ward, a C-circuit is used. Later on for any disconnection of circuit, endotracheal tube is clamped prior to disconnection.

The process of doffing has been clearly explained and specific sites designated as defined by infectious diseases team of the hospital. After the procedure is done, a system of transporting the patient to ward or ICU is followed. This is done with minimum number of staff members. The doctor, trained anesthesia technician and staff nurse are present in their personal protective gear. The porter is present wearing only a surgical mask and tasked with opening the door and operating the lift during the transfer.

CPR guidelines for the in-hospital cardiac arrests have also been modified. Firstly, any patient undergoing cardiac arrest is treated as COVID-19 positive and donning with appropriate PPEs is done before initiation of CPR. Secondly, in the event of a cardiac arrest, if a patient has a shock-able rhythm; three consecutive shocks are delivered before starting chest compressions. In addition to this, guidelines for CPR in ICU have also been revisited and necessary changes made to the criteria for initiating CPR and the process followed.

Furthermore, steps have been taken to spread awareness among members of staff by setting up multiple information signposts in different areas of the hospital and inculcating the need for self-assessment of their symptoms. They are strictly advised not to enter hospital premises if they exhibit symptoms but instead attend screening counters first.

\section{Preparation}

Personal protective equipment (PPEs) including N95 masks (3M, benehal masks), surgical masks, and gloves were made available by hospital administration. Face shields, headgear and Hazmat suits were locally manufactured (Table 1).

Use of PPE is a fundamental step towards reducing the risk of viral transmission. The sequence of donning and doffing was adapted from the Center of Disease Control and Prevention (CDC) and Public Health England (PHE) guidelines with a few appropriate modifications. $^{12-13}$ The rigorous use of PPEs is especially important for anesthetists because not only are they on the frontline dealing with COVID-19 patients but also perform procedures that are aerosol generating, thus exposing them to high viral load. ${ }^{14}$

Education of anesthesia personnel regarding changes in clinical practice was done in steps. Firstly, a team of two anesthetists was tasked with formulating an effective plan for training. 


\section{Shaukat Khanum Memorial Cancer Hospital \& Research Center -Department Of Anesthesia Tracheal Intubation Checklist - Suspected/Confirmed Covid 19 Patient}

\begin{tabular}{|c|c|c|c|}
\hline \multicolumn{4}{|c|}{ Personnel \& Roles } \\
\hline \multicolumn{3}{|c|}{$\begin{array}{l}\text { - Anaesthesia Doctor: Most experienced/ senior most } \\
\text { available } \\
\text { Anaesthesia Technician: Assistant, cricoid pressure, } \\
\text { McGrath \& HME procurement }\end{array}$} & $\begin{array}{ll}\text { - } & \text { Respiratory Therapist: Endotracheal } \\
\text { Tube, tie/ventilator management } \\
\text { - } \\
\text { Registered Nurse: Drug preparation and } \\
\text { administration }\end{array}$ \\
\hline \multirow{4}{*}{ 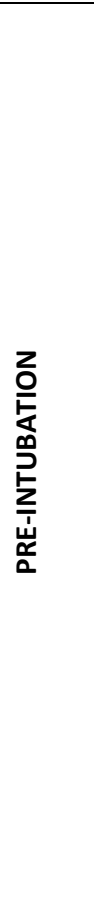 } & DONNING PPES (OUTSIDE THE ROOM) & \multicolumn{2}{|c|}{$\begin{array}{l}\text { - Hats } \\
\text { - Long sleeves gown } \\
\text { - N95/Surgical Mask } \\
\text { - Double gloves } \\
\text { - Eyes shield /Goggles }\end{array}$} \\
\hline & $\begin{array}{l}\text { EQUIPEMENT (OUTISDE THE } \\
\text { ROOM) }\end{array}$ & \multicolumn{2}{|c|}{$\begin{array}{l}\text { - BMV with HME } \\
\text { - Video-laryngoscope (McGrath with disposable blades, } \\
\text { Macintosh) } \\
\text { - Tracheal tubes/Ties } \\
\text { - Supraglottic airway devices } \\
\text { - Tray for disposing off laryngoscope blade } \\
\text { - Clamp }\end{array}$} \\
\hline & $\begin{array}{l}\text { DRUGS DRAWN UP IN SYRINGES } \\
\text { (PREPARE OUTSIDE THE ROOM) }\end{array}$ & \multicolumn{2}{|c|}{$\begin{array}{l}\text { - Induction agents (Midazolam/Ketamine/ Propofol) } \\
\text { - Paralytic agents (Suxamethonium } 1.5 \mathrm{mg} / \mathrm{kg} \text { ) } \\
\text { - Emergency drugs } \\
\text { - Vasopressor agents }\end{array}$} \\
\hline & $\begin{array}{l}\text { PATIENT (INSIDE PATIENTS } \\
\text { ROOM/OPERATING ROOM) }\end{array}$ & \multicolumn{2}{|c|}{$\begin{array}{l}\text { - Ensure fully functional IV line } \\
\text { - Standard monitoring } \\
\text { - Preparation of intubation equipment } \\
\text { - Working suction (preferably closed) } \\
\text { - Capnography }\end{array}$} \\
\hline & CONSIDER EARLY INTUBATION & \multicolumn{2}{|c|}{$\begin{array}{l}\text { - Optimize positioning/pre-oxygenation for } 5 \text { min with } 100 \% \mathrm{O}_{2} \text {. } \\
\text { - Video-laryngoscope } \\
\text { - RSI with no/minimal BMV } \\
\text { - If BMV, use two hands for good seal with low tidal volumes } \\
\text { - HME filter between mask and breathing circuit at all times } \\
\text { - Pass cuff } 1-2 \mathrm{~cm} \text { below the cords to avoid bronchial } \\
\text { - } \text { - Inflate cuff immediately after intubation \& refrain from positive } \\
\text { - pressure }\end{array}$} \\
\hline 点 $\frac{\text { o }}{\mathfrak{E}}$ & $\begin{array}{l}\text { - Confirm placement with capnograph } \\
\text { - Take off top gloves after intubation } \\
\text { - Minimize circuit disconnections, if } \\
\text { needed do it distal to HME filter; } \\
\text { clamp ETT before disconnection }\end{array}$ & \multicolumn{2}{|c|}{$\begin{array}{l}\text { - If COVID status not confirmed, deep tracheal aspirate for } \\
\text { virology (closed suction) } \\
\text { - Discard disposable equipment } \\
\text { - Decontaminate re-usable equipment as per hospital policy } \\
\text { - Doff PPE outside patient's room except N95 mask which will } \\
\text { be removed outside patient's room. }\end{array}$} \\
\hline \multicolumn{4}{|c|}{$\begin{array}{l}\text { > Difficult airway management as per DAS guidelines. > Donning and doffing as per hospital policy } \\
\text { > Avoid awake fiber-optic intubation and NIV > HME filter connected to ambo bag and circuit always } \\
\text { [Reference: Royal College of Anesthetists, Critical Care Medicine, Intensive Care Society.] }\end{array}$} \\
\hline
\end{tabular}


The formal training was started with anesthesia consultants. This group was encouraged to ask questions and clear any confusion. Subsequent sessions were held, which trained groups of anesthetists, starting from the senior most.

In an innovative move teaching session via simulation were introduced. The aim of these sessions was to familiarize anesthetists with airway management of suspected or confirmed COVID-19 patients and the proper sequence of donning and doffing of PPEs in order to prevent cross and self-contamination. Mannequins, props and a team of people playing roles made the experience realistic.

Anesthetists were briefed about the clinical scenarios which included cardiac arrest situations of suspected or confirmed COVID-19 patients and elective intubation of COVID-19 patients in ICUs. Before the scenario started, the anesthetist was informed of the patient condition. During the scenario an observer was tasked with identifying the good practices while pointing out room for improvement. After the scenario a de-briefing was done where relevant points were discussed in an open feedback session. The simulation training was offered multiple times over a period of 3 4 days. A session was held one week later where the anesthetists were asked to demonstrate the skills they had acquired during the training.

Other changes pertaining to equipment and medications were implemented rapidly; for example, in code blue situations, intubation trays and emergency drug boxes are made ready on a daily basis. The pharmacy department is responsible for the preparation and locking of drug boxes, they are then collected by the anesthesia technician and brought to OR daily. In the event of a code blue, anesthesia technician transports the drug boxes to the site of the code blue where registered nurse draws the medication and administers them as per physician orders. After use the drug boxes are returned to the pharmacy department for replenishing. (Box 1)

Similarly, intubation trays have been assembled, which contain disposable laryngoscope blades and endotracheal tubes of various sizes, supra-glottic airway devices, and most importantly, a videolaryngoscope such as the McGrath laryngoscope. This has been done to reduce cross contamination of the common equipment present in hospital stores. (Box 2)

\begin{tabular}{l} 
Box 1: Emergency drugs for code blue \\
scenario \\
Inj. Midazolam \\
\hline Inj. Propofol \\
\hline Inj. Ketamine \\
\hline Inj. Suxamethonium / Inj. Rocuronium \\
\hline Inj. Atracurium \\
\hline Inj. Atropine \\
\hline Inj. Adrenaline
\end{tabular}

\begin{tabular}{l} 
Box 2: Tray contents \\
Endotracheal tubes, assorted sizes \\
\hline Supraglottic airway device, LMA, ILMA, I-gel etc. \\
Assorted sizes \\
\hline Disposable laryngoscope blades, assorted sizes \\
\hline Video-laryngoscope \\
\hline Syringe for cuff inflation \\
\hline Cuff pressure meter \\
\hline Magil's forceps \\
\hline
\end{tabular}

\section{Implementation}

Counters have been set up at the entrance of operating rooms where the staff is screened daily for fever, cough and/or any other symptoms.

Operating rooms are designed to have a specified number of air changes per minute (greater than 20 per minute), which would reduce viral load inside them.

Multiple stations for hand washing or hand rub are already present in the operating rooms. The supplies are being consistently replenished by the pharmacy department of SKMCH \& RC to ensure frequent hand hygiene.

The supply of N95 respirators depends on the frequency of usage. Since operating room services have been resumed for urgent and emergency procedures, the consumption of PPEs is increasing. This is why the concept of rationing is important and we need to look into ways to preserve our supply.

One of the ways to conserve is to re-sterilize the N95 respirators used by the person intubating and extubating the patient so that it can be re-used the next day by same. The guidelines for re-sterilization were included after FDA approval for re-use. ${ }^{15}$ 
Table 1: Availability of selected PPEs at different areas of the hospital.

\begin{tabular}{|c|c|c|c|c|}
\hline Equipment & Operating Room & ICU & Covid Camp & Covid Ward \\
\hline N95 masks & $\sqrt{ }$ & $\sqrt{ }$ & $\sqrt{ }$ & $\sqrt{ }$ \\
\hline Surgical masks & $\sqrt{ }$ & $\sqrt{ }$ & $\sqrt{ }$ & $\sqrt{ }$ \\
\hline Surgical caps & $\sqrt{ }$ & $\sqrt{ }$ & & $\sqrt{ }$ \\
\hline Non-permeable gowns & $\sqrt{ }$ & & $\sqrt{ }$ & \\
\hline Hazmat suits & & $\sqrt{ }$ & & $\sqrt{ }$ \\
\hline Head gear/cap & $\sqrt{ }$ & $\sqrt{ }$ & & $\sqrt{ }$ \\
\hline Shoe covers & & $\sqrt{ }$ & & \\
\hline Visors/goggles & $\sqrt{ }$ & $\sqrt{ }$ & & $\sqrt{ }$ \\
\hline Double gloves & $\sqrt{ }$ & $\sqrt{ }$ & $\sqrt{ }$ & $\sqrt{ }$ \\
\hline Disposable plastic aprons & & $\sqrt{ }$ & $\sqrt{ }$ & $\sqrt{ }$ \\
\hline
\end{tabular}

A separate ICU for COVID-19 patients has been set up on one of the floors of the hospital. In addition to this, an isolation ward has been designated for patients requiring oxygen support or special care.

The hospital has laid much emphasis on the mental wellbeing of the personnel. The employees are urged to seek help from a peer if they were experiencing stress. However, if this does not suffice, they should turn to a senior or a consultant for guidance. If talking to a senior does not help, personnel are advised to reach out and talk to the Head of Department. If the issue remains unresolved, all employees are given the option to avail psychological support by an in-house psychologist and psychiatrist. Research regarding the potential impact of COVID-19 crisis on mental health of healthcare workers is underway. This is important because the pandemic is expected to take a toll on the mental health of healthcare workers since they are at greatest risk of contracting the disease. Fear of contagion is a grim reality in current situation. ${ }^{16}$

In addition to this, the infectious disease department of the hospital keeps the staff regularly updated with all the CDC and WHO guidelines through an email which is sent daily with recent changes highlighted. If the employees have further queries, they are free to contact the relevant department.

\section{Summary}

We have come to recognize the limitations of our healthcare system in the time of this crisis.
Preparations at Shaukat Khanum Hospital have been done keeping in view that systems that are not equipped tend to suffer more as illustrated by examples of even advanced healthcare systems being unable to meet the demands of an epidemic, in the face of inadequate planning. ${ }^{17}$

A worrying aspect is the sudden interruption of usual clinical practice, re-assignment of roles and the need to work in unfamiliar conditions. The massive changes that are occurring frequently might lead to slipping of the standards that may affect patient safety adversely. This has to be looked into by conducting frequent audits using existing key performance indexes and identifying any alarming trends.

As we are a cancer hospital, we are mindful of the impact of disrupting our elective surgical list on the work load and patient burden. On the other hand, our population is inherently immuno-compromised and therefore at risk and prevention was deemed to be better than treatment given the circumstances.

The addition of new guidelines to literature is an ongoing process. For example, The American Society of Anesthesiologists recently updated their guidelines regarding testing for coronavirus of patients scheduled for elective surgery. They stated that all patients should be tested for coronavirus and regardless of the test result, healthcare professionals are recommended to use PPEs since test sensitivity is limited. ${ }^{18}$ These guidelines were used as basis for commencement of elective surgery at our center. 
Current lack of clarity in our understanding of the disease means that we do not have ways to identify indicators to assess the adequacy of our preparations; such conclusions can only be drawn retrospectively. Our clinical practice is expected to undergo several reforms due to the rapidly changing dynamics of a new pandemic and scientific progress that guides evolution of new guidelines.

The way forward therefore, is a critical review of guidelines being implemented worldwide and customizing them according to need of the hour. Through a review of our preparations with limited resources we hope to serve as source of guidance for other systems struggling with a lack of means.

\section{Conflict of interest}

No conflict of interest declared by the authors. There was no financial assistance involved,

\section{Authors' contribution}

SAK: Concept, Literature search, Manuscript writing

WNA: Manuscript editing, Literature search

MHC, AAK: Literature search

AWK: Manuscript editing

\section{References}

1. Novel Coronavirus (2019-nCoV) SITUATION REPORT - 121 JANUARY 2020 [Internet]. Who.int. 2020 [cited 26 July 2020]. Available from: https://www.who.int/docs/defaultsource/coronaviruse/situation-reports/20200121-sitrep1-2019-ncov.pdf

2. Wu YC, Chen CS, Chan YJ. The outbreak of COVID19: An overview. J Chin Med Assoc. 2020;83(3):217220. [PubMed] [Free Full Text] DOI: $10.1097 / J C M A .0000000000000270$

3. Guo $Y-R$, Cao Q-D, Hong Z-S, Tan Y-Y, Chen S-D, Jin $\mathrm{H}-\mathrm{J}$, et al. The origin, transmission and clinical therapies on coronavirus disease 2019 (COVID-19) outbreak - an update on the status. Military Medical Research. 2020;7(1). [PubMed] [Free Full Text] DOI: $\underline{10.1186 / s 40779-020-00240-0}$

4. Coronavirus Disease (COVID-19) - events as they happen [Internet]. World Health Organization. World Health Organization; [cited 2020Apr16]. Available from: https://www.who.int/emergencies/diseases/novelcoronavirus-2019/events-as-they-happen (Accessed on: 16 April 2020)

5. Coronavirus Cases: [Internet]. Worldometer. [cited 16 April 2020]. Available from: https://www.worldometers.info/coronavirus/ (Accessed on: 11 May 2020

6. Goldsmith CS, Tatti KM, Ksiazek TG, Rollin PE, Comer JA, Lee WWet al. Ultrastructural characterization of SARS coronavirus. Emerg Infect Dis. 2004;10(2):320326. [PubMed] [Free Full Text] DOI: $10.3201 /$ eid1002.030913

7. Jamison DT, Gelband $\mathrm{H}$, Horton $\mathrm{S}$, Jha $\mathrm{P}$, Mock $\mathrm{CN}$, Nugent R. Disease Control Priorities, Third Edition (Volume 9) Improving Health and Reducing Poverty. Washington: World Bank Publications; 2017.

8. Lemon SM. Ethical and legal considerations in mitigating pandemic disease workshop summary. Washington, D.C.: National Academies Press; 2007.

9. Coccolini F, Perrone G, Chiarugi M, Di Marzo F, Ansaloni L, Scandroglio I, et al. Surgery in COVID-19 patients: operational directives. World J Emerg Surg. 2020;15(1):25. [PubMed] [Free Full Text] DOI: $\underline{10.1186 / s 13017-020-00307-2}$

10. Chen N, Zhou M, Dong X, Qu J, Gong F, Han Y, et al. Epidemiological and clinical characteristics of 99 cases of 2019 novel coronavirus pneumonia in Wuhan, China: a descriptive study. Lancet. 2020 Feb 15;395(10223):507-13. [PubMed] [Free Full Text] DOI: $10.1016 / S 0140-6736(20) 30211-7$

11. CDC - Hierarchy of Controls - NIOSH Workplace Safety and Health Topic [Internet]. Centers for Disease Control and Prevention. Centers for Disease Control and Prevention; 2015 [cited 5 May 2020]

12. SEQUENCE FOR PUTTING ON PERSONAL PROTECTIVE EQUIPMENT (PPE) [Internet]. Centers for Disease Control and Prevention. Centers for Disease Control and Prevention; [cited 16 April 2020]. Available from: https://www.cdc.gov/hai/pdfs/ppe/ppesequence.pdf Accessed on: 04/16/2020

13. Putting on (donning) personal protective equipment (PPE) for aerosol generating procedures (AGPS) [Internet]. PUBLIC HEALTH ENGLAND. PUBLIC HEALTH ENGLAND; [cited 16 April 2020]. Available from:

https://assets.publishing.service.gov.uk/government/up loads/system/uploads/attachment data/file/879103/PH E_COVID-19_Donning_quick_guide_gown_version.pdf Accessed on: 04/16/2020

14. Peng PWH, Ho PL, Hota SS. Outbreak of a new coronavirus: what anaesthetists should know. $\mathrm{Br} J$ Anaesth. 2020;124(5):497-501. [PubMed] [Free Full Text] DOI: $\underline{10.1016 / j . b j a .2020 .02 .008}$

15. Commissioner Oof the. Coronavirus (COVID-19) Update: FDA Issues Emergency Use Authorization to Decontaminate Millions of N95 Respirators [Internet]. U.S. Food and Drug Administration. FDA; [cited 5 May 2020]. Available from: https://www.fda.gov/newsevents/press-announcements/coronavirus-covid-19update-fda-issues-emergency-use-authorizationdecontaminate-millions-n95

16. Huang JZ, Han MF, Luo TD, Ren AK, Zhou XP. Zhonghua Lao Dong Wei Sheng Zhi Ye Bing Za Zhi. 
2020:38(3):192-195.

[PubMed]

DOI: $10.3760 / \mathrm{cma}$.j.cn121094-20200219-00063

17. Cavallo JJ, Donoho DA, Forman HP. Hospital Capacity and Operations in the Coronavirus Disease 2019 (COVID-19) Pandemic-Planning for the Nth Patient. JAMA Health Forum 2020 Mar 2 (Vol. 1, No. 3, pp. e200345-e200345). [Free Full Text]
18. The ASA and APSF Joint Statement on Perioperative Testing for the COVID-19 Virus [Internet]. The ASA and APSF Joint Statement on Perioperative Testing for the COVID-19 Virus | American Society of Anesthesiologists (ASA). [cited 5 May 2020]. Available from: https://www.asahq.org/aboutasa/newsroom/news-releases/2020/04/asa-and-apsfjoint-statement-on-perioperative-testing-for-the-covid$\underline{19 \text {-virus }}$ 